九州大学学術情報リポジトリ

Kyushu University Institutional Repository

Comparisons of Early Growth between Seedlings and Sprouts, and Relationship between Original Tree Size and Vigor of Sprouts of Pusania edulis

Ito, Satoshi

Laboratory of Silviculture, Faculty of Agriculture, Kyushu University

Yahata, Hisashi

Laboratory of Silviculture, Faculty of Agriculture, Kyushu University

Suzaki, Tamio

Laboratory of Silviculture, Faculty of Agriculture, Kyushu University

https://doi.org/10.5109/23890

出版情報: 九州大学大学院農学研究院紀要. 34 (1/2)，pp.77-94，1989-11. Kyushu University バージョン：

権利関係 : 


\title{
Comparisons of Early Growth between Seedlings and Sprouts, and Relationship between Original Tree Size and Vigor of Sprouts of Pusania edulis
}

\author{
Satoshi Ito, Hisashi Yahata and Tamio Suzaki \\ Laboratory of Silviculture, Faculty of Agriculture, \\ Kyushu University 46-03, Fukuoka 812, Japan
}

(Received May 29, 1989)

\begin{abstract}
Early growth characteristics were compared between seedlings and sprouts of Pasania edulis developed after clear cutting of the forest stand, and a relationship between the original plant size before cutting and the vigor of sprouts was also investigated. The early growth of sprouts during the first growing season were far greater than those of seedlings on both individual and unit area basis. The sprouts showed unique growth characteristics. They developed non-photosynthetic parts earlier than photosynthetic parts to expand foliage at more advantageous position which might be supported by the abundant reserved substances and large water and mineral absorbing capacity of the original root system compared with those of seedlings. The vigor of sprouts was closely related to the original plant size used in this study as an index of the amount of reserved substances. However, even if the number of sprouts per unit reserved substances decreased, use efficiency of reserved substance did not increase. This result may suggest the possibility that all of the reserved substances are not utilized for regrowth by sprouts.
\end{abstract}

\section{INTRODUCTION}

Sprouting is the most important type of vegetative propagation for hardwood forests (Kramer and Kozlowski, 1960). Sprouts have a certain significance in the forest regeneration process. Generally, in the process of forest regeneration, it is advantageous that the following generation such as seeds and seedlings always exist on the forest floor if they utilize the gaps which are less predictable as the sites of regeneration (Grime, 1979). However, an "advance reproduction" established in the understory is more important in the natural regeneration of many hardwood species (Tryon and Powell, 1984) because such species produce seeds intermittently. Also, ability of survival under unfavorable conditions such as indequate light environment under the canopy may raise the possibility of successful regeneration. Higo (1987) suggested that torelance should be discussed considering the ability of survival by vegetative reproduction.

Sprouts as one of the existing forms of advance reproduction play an important role in the process of regeneration. Importance of surviving of seedlings by sprouting after death or predation of top was reported in several deciduous trees, i.e., black cherry (Prunus serotina Erhr.) (Auclair, 1975), oak (Quercus alba L., etc.) (Merz and Boyce, 1956 ; Powell and Tryon, 1979 ; Tryon and Powell, 1984 ;Higo, 1987), Acer mono, Tilia japonica (Higo.1987), and warm-temperate broad-leaved trees, i. e., Cyclobalanopsis acuta (Okano, et al., 1988). The other examples as in a birch (Betula 
tremuloides) dwarf forest along the timber line (Okitsu, 1980), Japanese beech (Fagus japonica) forests (Tohyama, 1965 ; Ohkubo, et al., 1988) and hamabiwa (Litsea japonica) coastal dwarf forests (Ito, unpublished data) indicate that not only seedling sprouts but also sprouts flushed directly from the mother tree contribute to the forest regeneration.

On the other hand, sprouting ability is available for forestry. Up to now, the sprouting regeneration has been utilized in the forest managements which aim at production of small size woods as fuel woods, and recently its has been reconsidered with lack of resources of broad-leaved trees and with a rise of anticipation to the environmental conserving functions of forests in Japan. The primary merit of sprouting regeneration is emprically known as the fast early growth during several years after flushing compared with those of seedlings.

Some causes of this fast growth of sprouts could be as follows : great amount of reserved substances and advantage in absorbing water and minerals due to the existing roots. However, as most of studies on sprouts were focused on the technology of management, only limited information exists on ecophysiological characteristics of sprouts. Therefore, the studies on sprouts from the view point of ecophysiology are necessary.

The purpose of this paper is to investigate the superiority of sprouts through the comparisons of early growth between seedling and sprouts of Pasaniaedulis (Fagaceae) which is known by vigorous sprouting, and to describe the relationship between sprouting ability and reserved substances which is assumed to be one of the reasons of superiority of sprouts, for the first step of ecophysiological approach.

\section{MATERIALS AND METHODS}

Pasania edulis, investigated in this paper, is an evergreen broad-leaved tree growing in the warm-temperate zone in Japan, having a torelance to environmental stresses such as drought (Gyokusen, 1977), and is slightly intorelant to lack of light (Kusumoto, 1957). Originally, Pasania edulis may have adaptability to growth environments and appears widely as a component of evergreen broad-leaved forests in spite of their low coverage (Miyawaki, 1981; Fujiwara, 1981). Pasania edulis forests distribute widely along the coastal lowland in the northern part of Kyushu, Japan. The floristic composition, growth characteristics and production structure of these forests have been reported in previous paper (Ito, et al., 1988a). These forests, often dominated only by Pasaniaedulis, may be established under the influence of man-made factors, and early growth of sprouts after clear-cutting should be a main factor of the formation of that unique stand structure (Ito, et al., 1988a).

The stand studied is a typical Pasania edulis coppice forest which was $11.5 \mathrm{~m}$ in average height in tree layer and 34 years old, located in kitamatsuura-gun, Nagasaki Pref., i. e., in the northwest of Kyushu Island. A $16 \mathrm{~m} \mathrm{X} 16 \mathrm{~m}$ plot was settled in this stand. Vegetation and production structure were investigated in October 24, 1986, and all trees within the plot were cut down at about $10 \mathrm{~cm}$ above ground surface (Ito, et al., 1988a). A general condition and above ground biomass of surveyed stand before cutting are shown in Table 1 and 2, respectively. The forest canopy was thin, but showed very high density. Relative light intensity declined abruptly around the top of forest canopy, and was restricted at the low level of 1.6 or $2.0 \%$ on the forest floor. 
Table 1. General description of the surveyed plot.

\begin{tabular}{lcc}
\hline Altitude & $(\mathrm{m})$ & 150 \\
Slope direction & & $\mathrm{S} 82 \mathrm{E}$ \\
Inclination & $\left({ }^{\circ}\right)$ & 7.5 \\
Average DBH & $(\mathrm{cm})$ & 9.9 \\
Average height in the tree layer & $(\mathrm{N} \mathrm{o./ha)}$ & 11.5 \\
Tree density & $\left(\mathrm{m}^{2} / \mathrm{ha}\right)$ & 6210 \\
Basal area & $(\%)$ & 95.5 \\
Relative dominance of Pasania edulis & $(\% 1.7$ \\
\hline
\end{tabular}

Table 2. Above ground biomass biomass (dry weight), SLA and LAI of 34-year-old Pasania edulis coppice forest,

\begin{tabular}{|c|c|c|c|c|c|c|}
\hline \multirow{2}{*}{$\begin{array}{l}\text { Layer } \\
(\mathrm{m})\end{array}$} & \multicolumn{4}{|c|}{ Dry weight (ton/ha) } & \multirow{2}{*}{$\begin{array}{l}\text { S. L. A. } \\
\text { (ha/ton) }\end{array}$} & \multirow{2}{*}{$\begin{array}{l}\text { L. A. I. } \\
\text { (ha/ha) }\end{array}$} \\
\hline & Stem & Branch & Stem and Branch & Leaf & & \\
\hline $11.2 \sim$ & 0.01 & 0.82 & 0.83 & 2.69 & 45.8 & 1.23 \\
\hline $10.2-11.2$ & 0.21 & 8.72 & 8.54 & 6.43 & 50.0 & 3.21 \\
\hline $9.2-10.2$ & 1.34 & 10.76 & 11.51 & 0.58 & 60.0 & 0.35 \\
\hline $8.2 \sim 9.2$ & 3.71 & 7.12 & 10.92 & 0.01 & 70.2 & 0.01 \\
\hline $7.2 \sim 8.2$ & 6.81 & 5.81 & 12.62 & . & • & . \\
\hline $6.2 \sim 7.2$ & 11.34 & 3.42 & 14.76 & . & - & - \\
\hline $5.2 \sim 6.2$ & 15.06 & 0.80 & 15.86 & . & . & . \\
\hline $4.2 \sim 5.2$ & 19.43 & . & 19.43 & . & - & - \\
\hline $3.2 \sim 4.2$ & 22.36 & . & 22.36 & . & . & . \\
\hline $2.2 \sim 3.2$ & 25.41 & . & 25.41 & . & . & - \\
\hline $1.2 \sim 2.2$ & 27.70 & . & 27.70 & . & - & . \\
\hline $0.4 \sim 1.2$ & 26.61 & . & 26.61 & . & . & - \\
\hline Total & 159.97 & 44.77 & 204.73 & 9.70 & 53.2 & 4.80 \\
\hline
\end{tabular}

Stems of Pasania edulis were standing in high density with lack of sub-tree layer and with poor understory vegetation.

All seedlings and sprouts of Pasania edulis grown within the plot were measured in basal diameter and height, in December 10, 1987 when the first growing season ended. To compare the growth characteristics, 31 samples of seedlings and 67 samples of sprouts were collected at random from the outside of the plot but within the same stand in July 21 and December 10, 1987. After measuring basal diameter and height, samples were divided into each portions, i. e., stems, branches and leaves in both of seedlings and sprouts and roots in seedling, and oven-dry weight were measured respectively. Beside, we assumed that there were no difference in the light condition during the growth between seedlings and sprouts because only few pioneer species invaded into the plot and canopy had not been closed when the samples were collected.

Many researchers have reported that vigor of sprouts related to the size and age of stump or season of cutting (e. g., Miyoshi, 1959 ; McDonald and Powell, 1983 ; Mroz, et al., 1985 ; Kamitani, 1986). Although this may indicate the relationship between vigor of sprouts and reserved substances, it is difficult, and often seems impossible particularly for large materials in the field condition, to measure the reserved substances in the root system and vigor of sprouts at the same time. Diameters of stumps 
which were used in many analyses of sprouts fluctuate largely affected by stem forms and cutting heights. So we adopted the above ground biomass before cutting as an index of the amount of reserved substances because it is considered to be closely related to the amount of roots (Karisumi, 1979) and consequently related to the amount of reserved substances.

In this paper, we did not classify the sprouts by the flushing positions because of the reasons described later. But, actual sprouts included abnormal shoots which conglutinated each other at the base of shoots forming clumps. So we used only the normal shoots in the comparisons of growth characteristics, and abnormal shoots were taken into consideration in the analysis of relationship between the vigor of sprouts and reserved substances. In addition, several original stems also conglutinated near the base before cutting because these forests had been managed by repetition of coppicing, making it difficult to clear the stem where each sprouts flushed. Therefore, the relationship between vigor of sprouts and reserved substances were analyzed by assuming one clump of original stumps to be one individual in this paper.

\section{RESULTS}

\section{Growth characteristics}

Table 3 and Table 4 show allometric relationships between the measured size and the biomass for sprouts and seedlings, respectively. In D-H (D, basal diameter; $\mathrm{H}$, tree height) relationships (Fig. 1-(a)), a coefficient of allometry, b of the seedlings was almost same as common values of evergreen broad-leaved forests, but that of sprouts was about two times greater. This indicates that in sprouts relative elongation rate is higher when compared with relative radial growth rate as observed in pioneer tree species (Yoda, 1971). This is one of the differences of early growth between sprouts and seedlings.

W (L)-W (S+B) relationships (Fig. 1-(b)) show that the relative growth rates (RGR) of photosynthetic parts is much lower than that of non-photosynthetic parts in seedlings compared with those of sprouts. This results in the difference in the changes of C-F ratios (ratios of non-photosynthetic parts to photosynthetic parts), shown in Fig. 2-(a), which are supposed to affect the productivity (Iwaki, 1958). The C-F ratios of seedlings are significantly lower $(\mathrm{p}<0.001)$ than those of sprouts in the comparison of above ground, and these differences between seedlings and sprouts are extremely larger in smaller size, i. e., earlier stage of growth. But, the non-photosynthetic parts should include roots. Fig. 2-(b) shows another comparison where the roots of only seedlings were added to the non-photosynthetic parts, supposing that new roots had not been formed and that maintenance respiration of the original roots had been maintained with the reserved substances in sprouts until they were sampled. Although the $\mathrm{C}-\mathrm{F}$ ratios of seedlings became to resemble to those of sprouts by this modification, the former are significantly lower than the latter $(\mathrm{p}<0.05)$.

\section{Net growth during the first growing season}

Net growth of the sprouts and the seedlings per individual during the first growing season estimated by the allometric relationships are shown respectively in Table 5 . Generally, sprouts showed obviously faster growth than seedlings, particulaly in stems 
Table 3. Allometric relationships of sprouts of Pasania edulis.

\begin{tabular}{ccccc}
\hline X* & \multicolumn{1}{c}{ Y } & a & b & r \\
\hline D & H & 0.161 & 1.826 & $0.909^{* * *}$ \\
$\mathrm{D}^{2} \mathrm{H}$ & $\mathrm{W}(\mathrm{L})^{* *}$ & -3.342 & 1.139 & $0.941^{* * *}$ \\
$\mathrm{D}^{2} \mathrm{H}$ & $\mathrm{W}(\mathrm{S}+\mathrm{B})$ & -2.515 & 0.923 & $0.983^{* * *}$ \\
$\mathrm{D}^{2} \mathrm{H}$ & $\mathrm{W}(\mathrm{L}+\mathrm{S}+\mathrm{B})$ & -2.468 & 0.994 & $0.978^{* * *}$ \\
$\mathrm{~W}(\mathrm{~S}+\mathrm{B})$ & $\mathrm{W}(\mathrm{L})$ & -0.241 & 1.224 & $0.950^{* * *}$ \\
\hline
\end{tabular}

$* \log \mathrm{Y}=\mathrm{a}+\mathrm{b} \log \mathrm{X} ; \mathrm{r}$, correlation coefficient

** D, Basal diameter ; H, Tree height ; W (L), Leaf weight ; W (S + B), Stem and branch weight : $\mathrm{W}(\mathrm{L}+\mathrm{S}+\mathrm{B})$, Whole shoot weight above ground

${ }^{* * *} \alpha<0.001$

Table 4. Allometric relationships of seedlings of Pasania edulis.

\begin{tabular}{clrll}
\hline $\mathrm{X}^{*}$ & \multicolumn{1}{c}{$\mathbf{Y}$} & $\mathrm{a}$ & $\mathrm{b}$ & $\mathrm{r}$ \\
\hline $\mathrm{D}$ & \multicolumn{1}{c}{$\mathrm{H}$} & 0.787 & 0.905 & $0.881^{* * *}$ \\
$\mathrm{D}^{2} \mathrm{H}$ & $\mathrm{W}(\mathrm{L})^{* *}$ & -1.545 & 0.674 & $0.930^{* * *}$ \\
$\mathrm{D}^{2} \mathrm{H}$ & $\mathrm{W}(\mathrm{S}+\mathrm{B})$ & -1.937 & 0.701 & $0.931^{\prime \prime}$ \\
$\mathrm{D}^{2} \mathrm{H}$ & $\mathrm{W}(\mathrm{L}+\mathrm{S}+\mathrm{B})$ & -1.367 & 0.672 & $0.950^{* * *}$ \\
$\mathrm{D}^{2} \mathrm{H}$ & $\mathrm{W}(\mathrm{R})$ & -1.350 & 0.599 & $0.912^{* * *}$ \\
$\mathrm{D}^{2} \mathrm{H}$ & $\mathrm{W}(\mathrm{L}+\mathrm{S}+\mathrm{B}+\mathrm{R})$ & -1.133 & 0.645 & $0.952^{* * *}$ \\
$\mathrm{~W}(\mathrm{~S}+\mathrm{B})$ & $\mathrm{W}(\mathrm{L})$ & -1.313 & 0.860 & $0.894^{* * *}$ \\
$\mathrm{~W}(\mathrm{~S}+\mathrm{B}+\mathrm{L})$ & $\mathrm{W}(\mathrm{R})$ & -0.883 & 0.805 & $0.918^{* * *}$ \\
\hline
\end{tabular}

* $\log \mathrm{Y}=\mathrm{a}+\mathrm{b} \log \mathrm{X} ; \mathrm{r}$, correlation coefficient

** D, Basal diameter ; H, Tree height ; W (L), Leaf weight ; W (S+ B), Stem and branch weight : W $(\mathrm{L}+\mathrm{S}+\mathrm{B})$, Whole shoot weight above ground ; W $(\mathrm{R})$, Root weitht ; W $(\mathrm{L}+$ $\mathrm{S}+\mathrm{B}+\mathrm{R}+$ ), Whole weight

${ }^{* * *} \alpha<0.001$

and branches. Table 6 shows the net growth at the end of the growing season where the above ground biomass of the seedlings are less than $2 \%$ of those of sprouts because of the very small numbers of the seedlings.

\section{R elationship between the original tree size and the vigor of sprouts}

As shown in Fig. 3 and 4, allometric relationships between the original above ground biomass and $\mathrm{D}^{2} \mathrm{H}$ for the trees before cutting and between dry weight of whole shoot and $\mathrm{H}$ for the sprouts were obtained, respectively. To make the relationship between the original above ground biomass and "vigor of sprouts clear, the original above ground biomass before cutting ( $W a$ ) and net growth (total dry weight at the end of the first growing season) of sprouts per stump ( $W s)$ were estimated for all clumps of stumps in the plot from the results of Fig. 3 and Fig. 4, and shown in Fig. 5. Although the plot for the stumps were scattered widely in Fig. 5, we could obtain high correlations by dividing stumps into two types : normal stumps which include abnormal shoots less than $2 / 3$ of all shoots, and abnormal stumps which include abnormal shoots more than $2 / 3$ of all shoots. There was a tendency that $W s$ of the sprouts were greater in normal stumps than in abnormal stumps, indicating the greater vigor of sprouts in normal stumps. Relationships between $W a$ and the numbers of sprouts per stump $(N)$ are shown in the same way in Fig. 6, where such a difference between 


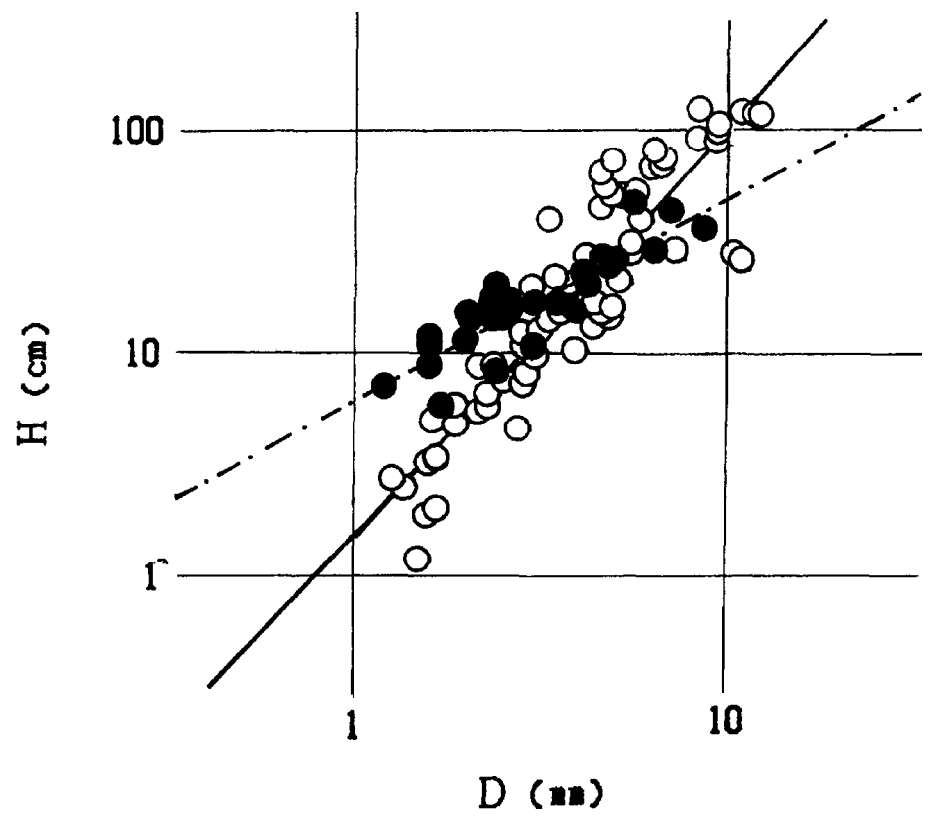

Fig. I-(a) Allomertic relationships between $\mathrm{D}$ and $\mathrm{H}$ of sprouts (open circles and solid line) and seedlings (closed circles and broken line) of Pasania edulis.

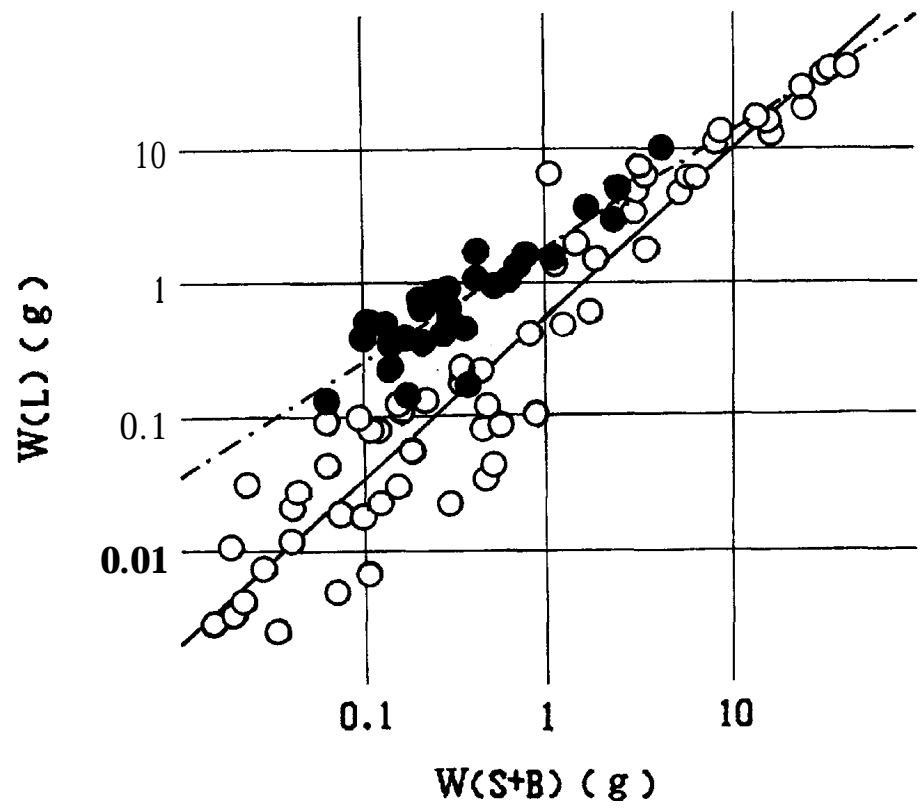

Fig. 1-(b) Allomertic relationships between dry weight of stems and branches (W $(\mathrm{S}+\mathrm{B})$ ) and dry weight of leaves (W (L)) of sprouts and seedlings of Pasania edulis. Symbols and lines are the same in Fig. 1 (a). 


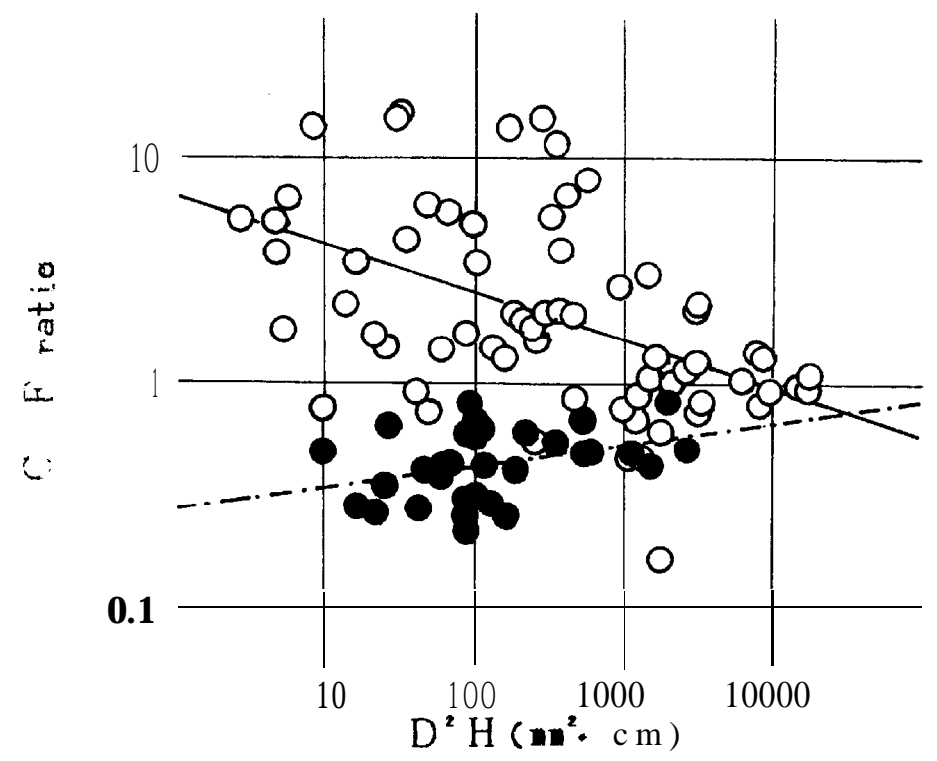

Fig. 2-(a) Relationships between $\mathrm{D}^{2} \mathrm{H}$ and C-F ratio of sprouts and seedlings of Pasaniaedulis. Symbols and lines are the same in Fig. 1 (a).

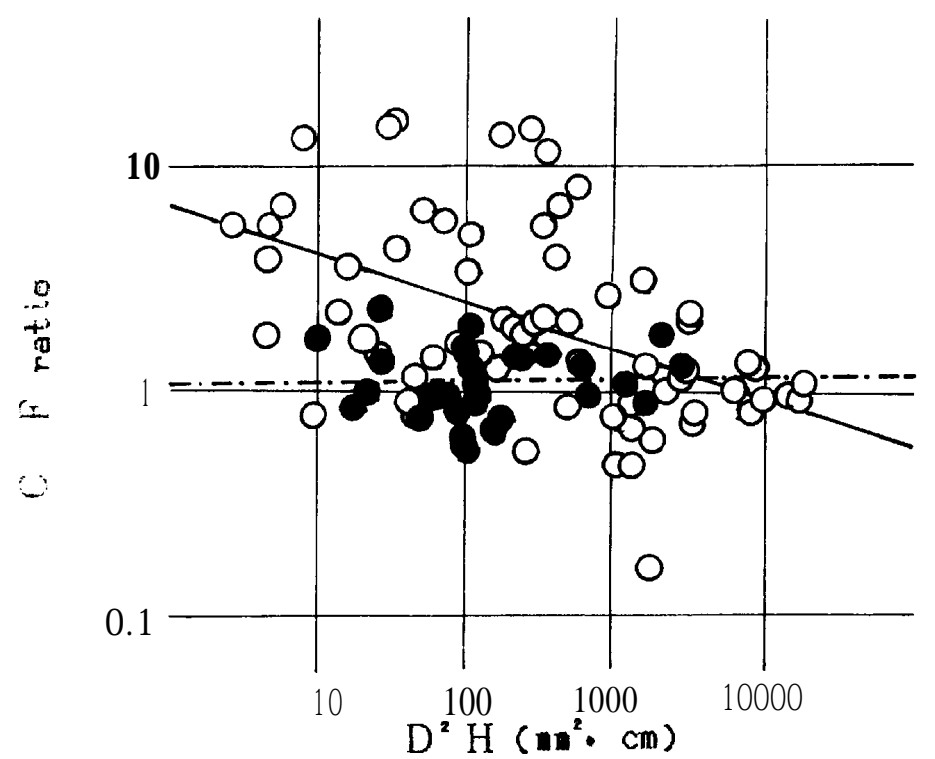

Fig. 2-(b) Relationships between $\mathrm{D}^{2} \mathrm{H}$ and $\mathrm{C}-\mathrm{F}$ ratio of sprouts and seedlings of Pasania edulis.

Non-photosynthetic organ (C) of seedlings includes root. Symbols and lines are the same in Fig. 1 (a).

normal stumps and abnormal stumps as in Fig. 5 is not observed. Table 7 shows the means and standard deviations of $W s$ and $N$ of each type of stumps. $W a$ fluctuates 
Table 5. Net growth of sprouts and seedlings of Pasania edulis per individual shoot during the first growing season after clear cutting.

\begin{tabular}{|c|c|c|c|c|c|c|c|c|}
\hline & \multirow{2}{*}{$\begin{array}{c}\text { Basal } \\
\text { Diameter } \\
(\mathrm{mm})\end{array}$} & \multirow{2}{*}{$\begin{array}{c}\text { Height } \\
(\mathrm{cm})\end{array}$} & \multicolumn{6}{|c|}{ Dry Weight (g) } \\
\hline & & & Leaf & Stem+Branch & Whole & Shoot & Root & Whole Individual \\
\hline \multirow{3}{*}{$\begin{array}{l}\text { Sprouts } \\
\text { Seedlings }\end{array}$} & $\begin{array}{l}-5.33^{\prime} \\
1.99\end{array}$ & $\begin{array}{l}38.49 \\
28.09\end{array}$ & $\begin{array}{r}3.025 \\
5.239\end{array}$ & $\overline{4.400}^{3.179}$ & & 9.734 & . & $\cdot$ \\
\hline & -3.40 & -13.87 & -0.973 & -0.460 & & -1.450 & -0.663 & -2.136 \\
\hline & 1.31 & 6.29 & 0.779 & 0.385 & & 1.156 & 0.464 & 1.625 \\
\hline
\end{tabular}

* Mean

S. D.

Table 6. Net growth of sprouts and seedlings of Pasania edulis per unit area during the first growing season after cfear cutting.

\begin{tabular}{lcrrccc}
\hline & \multirow{2}{*}{$\begin{array}{c}\text { Number of } \\
\text { Individuals } \\
\text { (No.) }\end{array}$} & Leaf & Stem+ Branch & Whole Shoot & Root & Whole Individual \\
\cline { 3 - 7 } & 78438 & 237.40 & 249.51 & 486.90 & & Dry Weight (kg/ha) \\
\hline Sprouts & 535 & 5.21 & 2.46 & 7.67 & 3.55 & $\mathbf{1 1 . 2 2}$ \\
Seedlings & & & & &
\end{tabular}

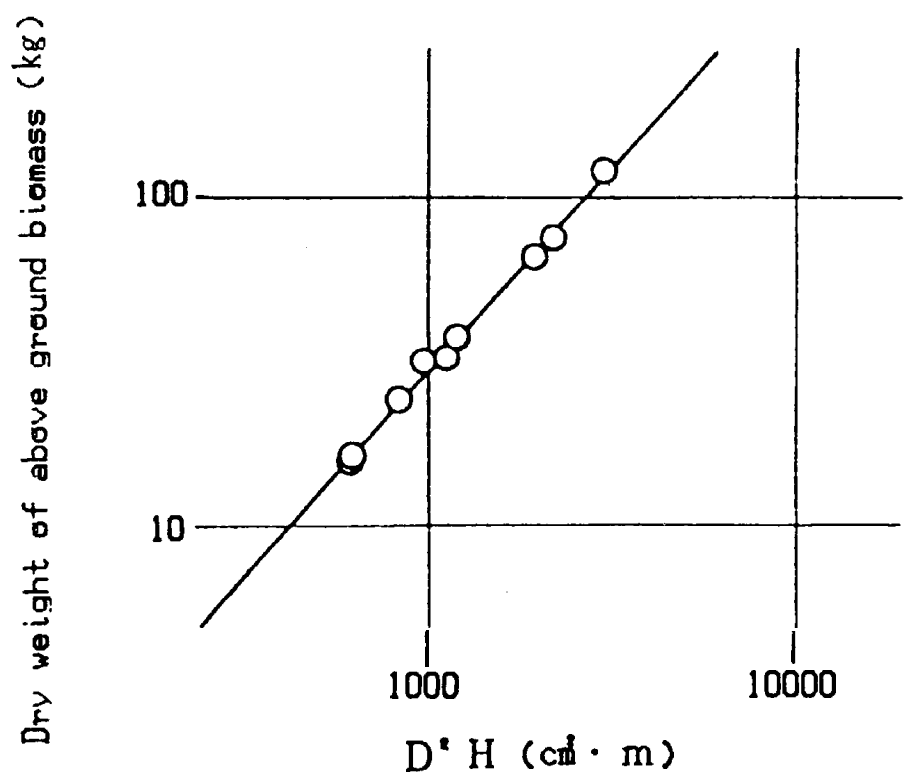

Fig. 3. An allomertic relationship between $D^{2} \mathrm{H}$ and above ground biomass of 34-year-old trees of Pasania edulis.

$$
\log (\text { Dry weight })=-2.263+1.246 \times \log \left(\mathrm{D}^{2} \mathrm{H}\right) \quad \mathrm{r}=0.997(\mathrm{P}<0.001)
$$

largely in both types, but abnormal shoots seem to be apt to occur on smaller stumps. The value of $W s$ is higher in normal stumps reflecting the difference in $W a$ and difference of vigor of sprouts shown in Fig. 5. 


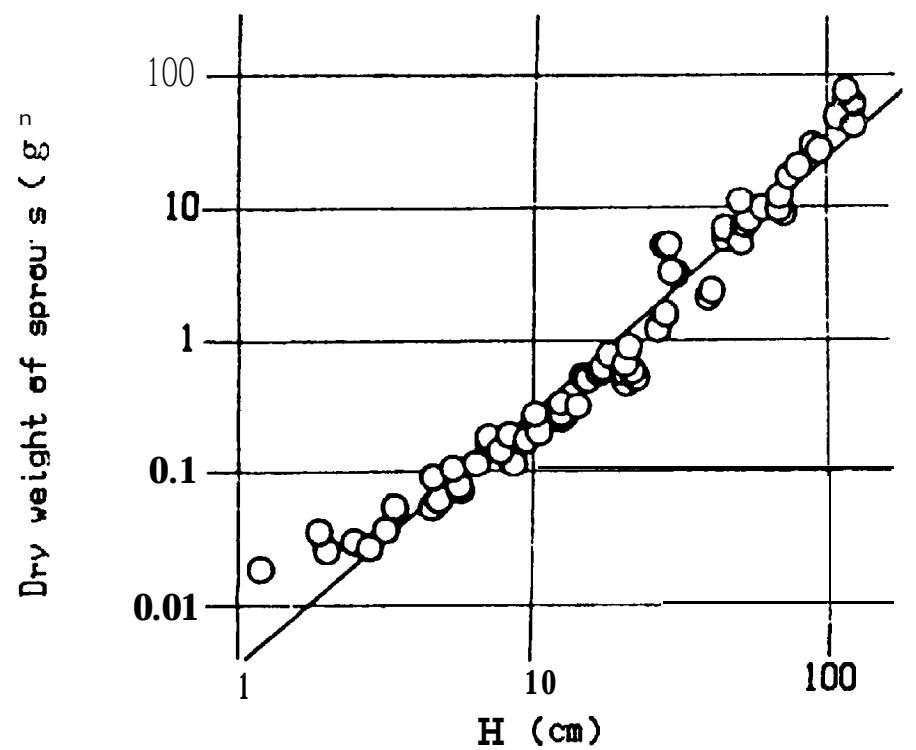

Fig. 4. An allomertic relationship between tree height $(\mathrm{H})$ and dry weight of sprouts of Pasania edulis.

$\log ($ Dry weight $)=-2.458+1.936 \times \log (H) \quad r=0.978(P<0.001)$

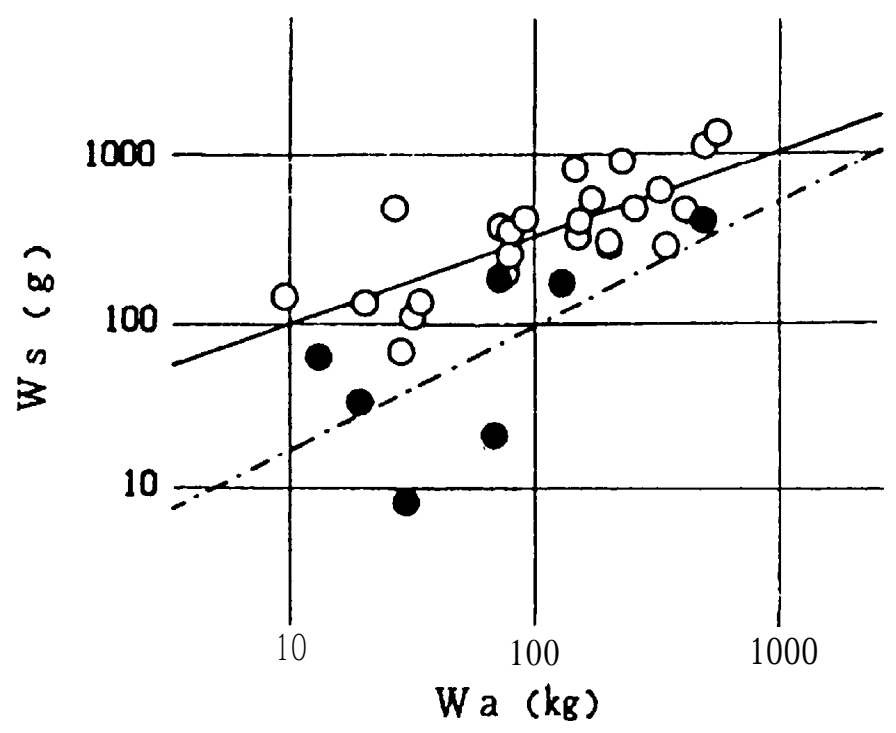

Fig. 5. Relationships between original above ground biomass before cutting ( $\mathbf{W}$ a) and total dry weight of sprouts per stump at the end of the first growing season $\left(W_{s}\right)$ of Pasania edulis.

Open circles and solid line, stumps including abnormal shoots less than $2 / 3$ of all sprouts $: \log (W s)=1.448+0.529 \times \log (W a) \quad r=0.757(P<0.001)$;

Closed circles and broken line, stumps including abnormal shoots more than $2 / 3$ of all sprouts : $\log \left(W_{s}\right)=0.472+0.771 \log (\mathrm{Wa}) \quad \mathrm{r}=0.675(\mathrm{P}<0.1)$. 


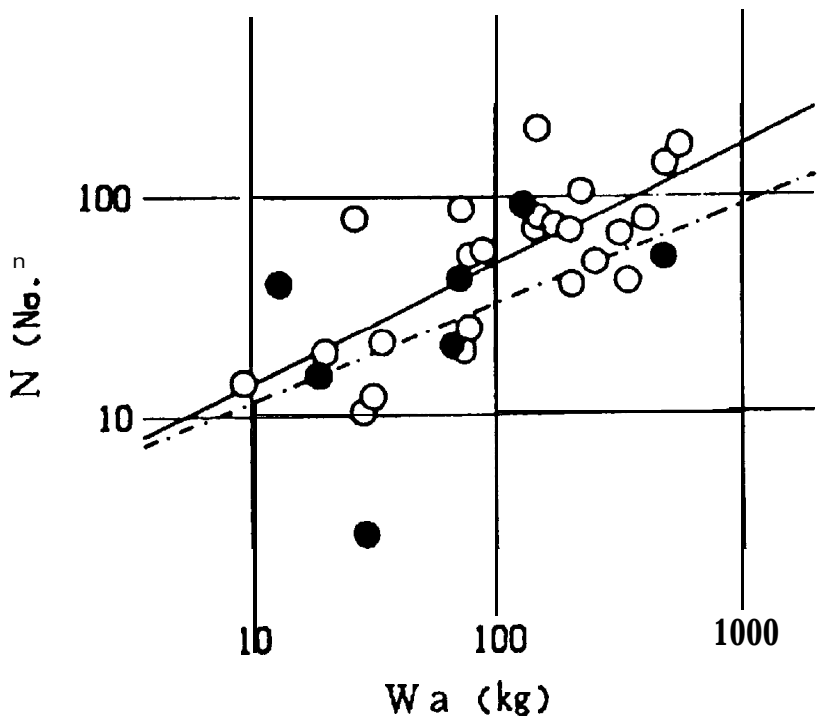

Fig. 6. Relationships between original above ground biomass before cutting $(W a)$ and number of sprouts per stump at the end of the first growing season $(N)$ of Pasania edulis. Symbols and lines are the same in Fig. 5.

Solid line: $\log (N)=0.613+0.545 \times \log (W a) \quad r=0.718(P<0.001)$;

Broken line $: \log (N)=0.632+0.453 \times \log (W a) \quad r=0.488$ (not significant).

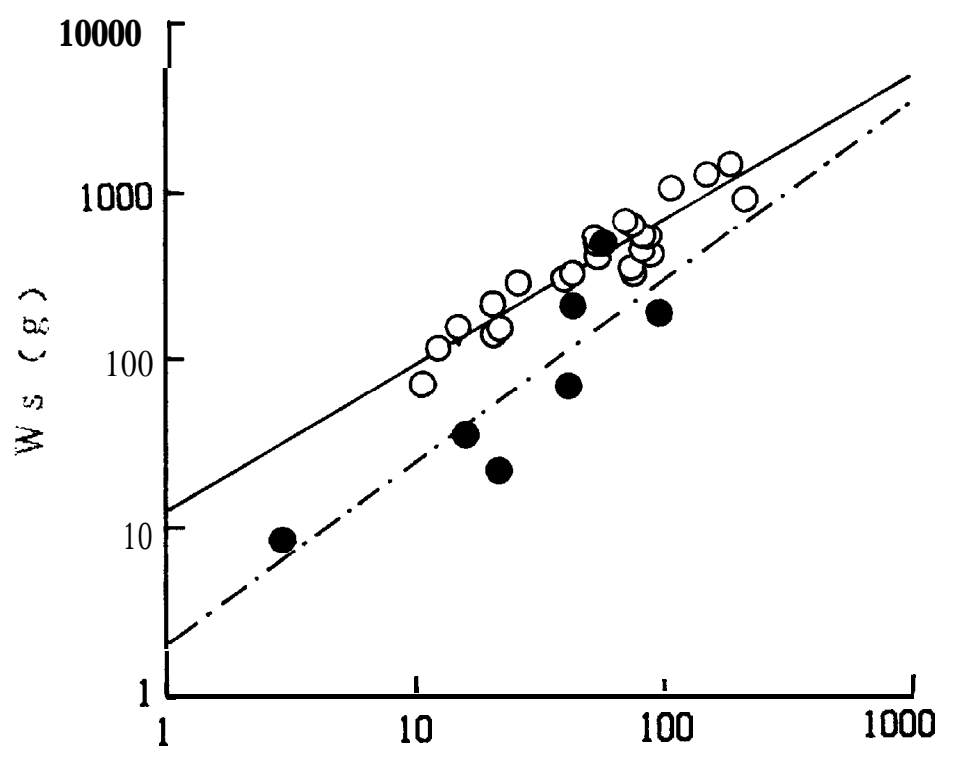

$\mathrm{N}$ (No.)

Fig. 7. Relationships between number of sprouts per stump $(N)$ and total dry weight of sprouts per stump ( $W s$ ) of Pasania edulis at the end of the first growing season. Symbols and lines are the same in Fig. 5.

Solid line $: \log \left(W^{\prime} s\right)=1.087-t 0.863 \times \log (N) \quad r=0.938(\mathrm{P}<0.001)$;

Broken line $: \log (\mathbf{W s})=\mathbf{0 . 2 9 2}+1.079 \times \log (N) \quad r=0.876(\mathrm{P}<0.001)$. 


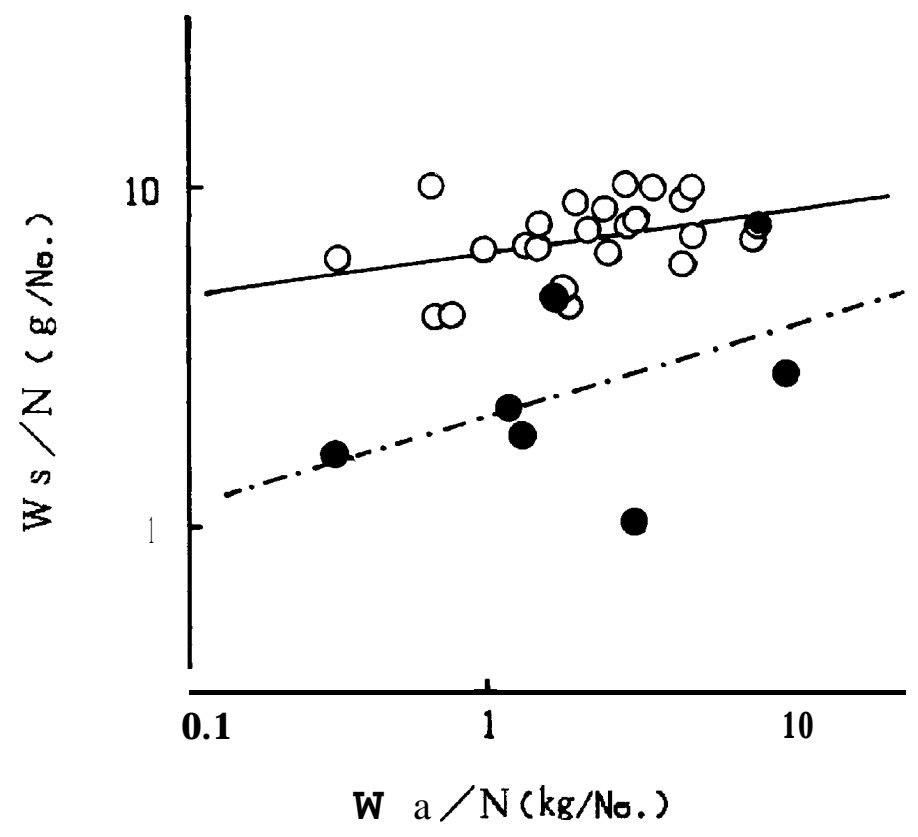

Fig. 8. Relationships between original above ground biomass per individual sprout $(\mathrm{Wa} / \mathrm{N})$ and mean dry weight of individual sprout $\left(W_{s} / N\right)$ of Pasania edulis at the end of the first growing season. Symbols and lines are the same in Fig. 5.

Solid lines: $\log (W s / N)=0.801+0.129 \times \log (W a / N) \quad r=0.340(\mathrm{P}<0.1)$ :

Broken lines $: \log \left(W_{S} / N\right)=0.316+0.262 \times \log (W a / N) \quad r=0.461$ (not significant).

Table 7. Number and biomass of sprouts of Pasania edulis per stump at the end of thefirst growing season after clear cutting.

\begin{tabular}{|c|c|c|c|c|}
\hline & & $\begin{array}{l}\text { Stumps including abnormal } \\
\text { shoots less than } \\
2 / 3 \text { of all sprouts }\end{array}$ & $\begin{array}{l}\text { Stumps including abnormal } \\
\text { shoots more than } \\
2 / 3 \text { of all sprouts }\end{array}$ & $\begin{array}{c}\text { All } \\
\text { Stumps }\end{array}$ \\
\hline \multirow[t]{2}{*}{$W a^{*}$} & (kg/stump) & $177.0^{* *}$ & 117.9 & 163.7 \\
\hline & & 152.7 & 155.5 & 155.3 \\
\hline \multirow[t]{2}{*}{$\mathrm{N}$} & (No./stump) & 71.8 & 40.4 & 64.8 \\
\hline & & 53.1 & 29.2 & 50.5 \\
\hline \multirow[t]{2}{*}{ ws } & (g/stump) & 482.8 & 139.2 & 405.2 \\
\hline & & 353.0 & 147.4 & 349.3 \\
\hline
\end{tabular}

*Wa, Original above ground biomass before clear cutting ; $N$, Number of sprouts per stump ;

Ws, Dry weight of sprouts per stump at the end of the first growing season.

** Mean

S. D.

Logarithmic linear relationships $(\log \mathrm{Y}=\mathrm{a}+\mathrm{b} \log \mathrm{X})$ can be fitted between $W s$ and $\mathrm{N}$ for each type of stumps with high correlations (Fig. 7). Dry weight of individual shoot of abnormal stumps are smaller than those of normal stumps.

Fig. 8 shows the relationships between $W a / N$ and $W s / N$. If the quantity of 


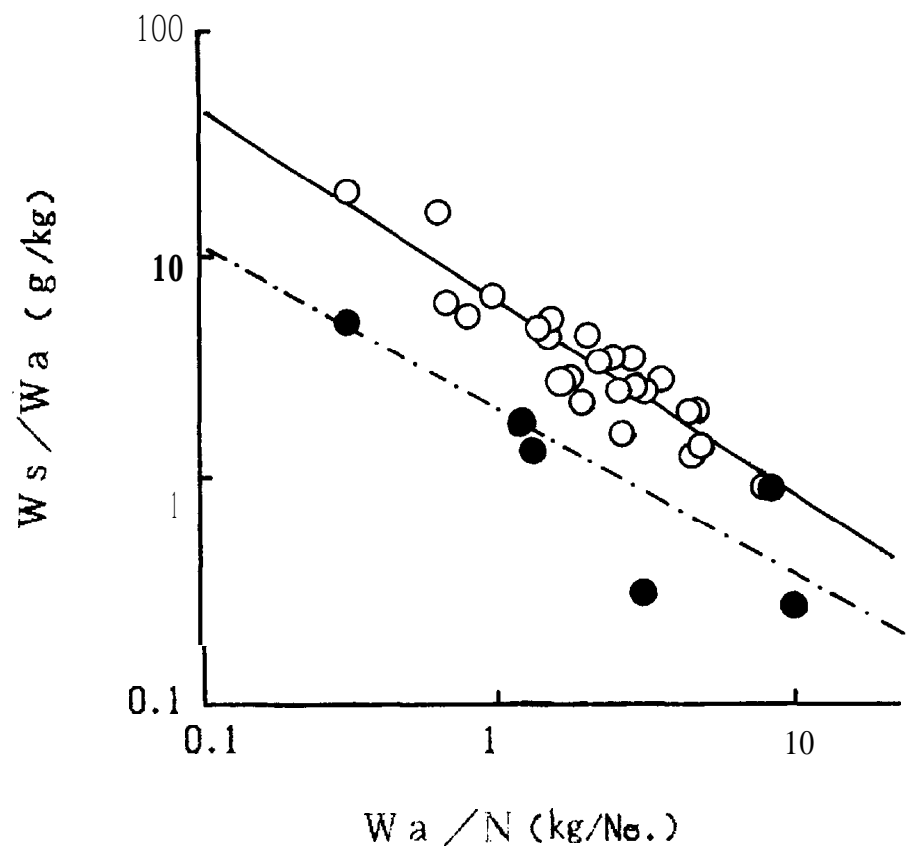

Fig. 9. Relationships between original above ground biomass per individual sprout $(\mathrm{Wa} / \mathrm{N})$ and the use efficiency of reserved substance of sprouts ( Ws $/ \mathrm{Wa}$ ) of Pasania edulis at the end of the first growing season. Symbols and lines are the same in Fig. 5. Solid lines : $\log \left(W_{s} / W a\right)=0.801+0.871 \times \log \mathrm{pV}(W a / N) \quad \mathrm{r}=0.926(\mathrm{P}<0.001)$ : Broken lines : $\log (W s / W a)=0.316+0.738 \times \operatorname{LogpV}(W a / N) \quad r=0.826(\mathrm{P}<0.01)$.

reserved substances are proportional to the plant size, we can assume $W a / N$ as an index of the quota of reserved substances to the sprout. According to this approximation, we can expect some positive correlations between the quota of reserved substances and $W s / N$, the mean growth of sprouts, and it was actually true. Although, the increases in $W s / N$ with $W a / N$ are very small. Fig. 9 shows relationships between $W a / N$ and $W s / W a$ which may be regarded as a use efficiency of the reserved substance. Here, negative correlations are obtained in both types, and the use efficiency of the reserved dubstance was lower in abnormal stumps than in normal stumps.

\section{DISCUSSION}

\section{M orphology of sprouts}

In the studies on sprouts, the definition and classification of sprouts is very important and should be commented in advance, since they differ depending on researchers.

Several researchers classified sprouts by flushing positions (Kramer and Kozlowski, 1960 ; Hashizume, 1984 ; Kamitani, 1986), but classification respecting to the primordia of sprouts may be rather important considering their ecological significance because definite buds were formed in advance and have been maintained until they 
actually become to be required for regrowth. Kramer and Kozlowski (1960) classified sprouts into two types : stump sprouts which flush from dormant buds and stool sprouts develop from adventitious buds which are formed between stem and bark. Zimmermann and Brown (1971) proposed, however, that definite buds embedded in the periderm of branch and stem which were referred to as dormant buds should be defined as the term of suppressed buds because they are active during much of the growing season in laying down new leaf and scale primordia and in keeping pace with radially expanding cambium. Shidei (1979) referred to dormant buds those which did not flush across spring and buried in xylem as latent buds. The latent buds referred by Shidei (1979) may be almost same as suppressed buds.

Several tree species, i. e., aspen (Populus tremula) (Eliasson, 1961), sweetgum (Liquidambar styraciflua L.) (Kormanik and Brown, 1967) and American beech (Fagus grandifolia) (Ward, 1961; Jones and Raynal, 1986, 1987, 1988) try to reproduce by root sucker. Primordia of root sucker occures in the following two ways ; definite buds such as suppressed buds as in sweetgum (Kormanik and Brown, 1967) and adventitious buds as in American beech (Robert and Dudley, 1986, 1987).

There are several studies on Quercus spp. growing in Japan. Hasegawa (1985), who investigated the distribution, morphology and growth of buds on the root collar of Quercus dentata, considered that those buds are latent buds because they can assume from their morphology to be severely suppressed shoots. Hashizume (1984) reported that primordia of sprouts were formed around the cambium in Quercus serrata and around the cork-cambium in Quercus acutissima, and that both of them were adventitious. Nevertheless, Gyokusen (1987a) observed that sprouts flushed from only the positions where axillary buds had existed, and that there were vascular traces connecting to the pith from the buds which were regarded as primordia of sprouts. From these observation, he concluded that primodia of sprouts of Quercus acutissima were latent buds. Further, he found that positions and distribution of latent buds in the stems of mature Quercus acutissima were remarkably resemble to those of axillary buds, and suggested that latent buds of Quercus acutissima originate from axillary buds (Gyokusen, 1987b).

In Pasania edulis, we can observe many latent buds with vascular traces connecting to the pith, and these buds are considered to originate from axillary buds. Sprouts also have vascular traces from the pith. Moreover, those described above do not change even if the flushing positions are low enough to be underground. It is, therefore, considered that primordia of sprouts of Pasania edulis are latent buds in the same way as Gyokusen's observation on Quercus acutissima (Gyokusen, 1987a,1987b), and there were no need to classify sprouts by flushing positions in this paper.

In this work, many abnormal shoots were recognized in sprouts of Pasaniaedulis, but the causes of them are not found yet. The abnormal shoots are commonly observed in Pasania edulis coppice forests and characterized by their morphological features, i. e., stout stem and meager foliage. They also shows different patterns of flushing and death from normal shoots (Ito et al., 1988b). In Pasania edulis, abnormal shoots flushed from stems or branches of mature trees are often observed, and these abnormal shoots showing unsatisfactory elongation and forming clumps are similar to those of sprouts which develop after cutting. However, their relationship had not been confirmed. It is difficult from their morphology to infer the cause which the abnormal 
shoot resulted from, i. e., some adventitious causes, continuous emergences of axillary buds within a latent bud or morbid causes. No fungi was detected from the abnormal shoots.

\section{Comparisons of early growth chracteristics between seedling and sprouts}

In comparison of above ground matter economy during the first growing season, more advantageous dry matter allocation in terms of increasing the photosynthetic organ was recognized in seedlings (Fig. 2-(a)) which showed even slower growth than sprouts, and this tendency did not change even when considering new roots of seedlings (Fig. 2-(b)). Higo (1986) reported that seedling sprouts, and seedling layers of Quercus mongolica var. grosseserrata, Tilia japonica and Acer mono, which are the main components of cool-temperate broad-leaved forests and coniferous-broad-leaved mixed forests, showed slightly higher the C-F ratios than intact seedlings in spite of their large fluctuations. His results coincide with those of present study. In Pasania edulis, however, the C-F ratios of seedlings increase slightly with plant sizes, and those of sprouts decrease abruptly (Fig. 2-(a)). This results lead to a conclusion with the result of D-H relationships (Fig. 1-(a)) as follows. At the early growth stage, seedlings adopt the growth to develop photosynthetic parts rather than non-photosynthetic parts. On the other hand, sprouts can adopt the growth to develop non-photosynthetic parts earlier than photosynthetic parts to expand foliage at more advantageous (upper) position.

The unique growth characteristics of sprouts described above are very advantageous strategy which are considered to result from the following reasons ; 1) it is not necessary to expand the foliage and roots at early stage because of their abundant reserved substances, 2) water stress hardly occur even if distance of water transport is long because of high water conductance from soil to leaf (Ito, unpublished data), 3) dry matter production after leaf expansion is ensured by high productivities of unit leaf area (Blake, 1980 ; Tschaplinski and Blake, 1989 ;Ito and Suzaki, 1989).

Johnson (1979) suggested that many clumps of the new sprouts which are rapidly changing structurally and functionally in oak (Quercus alba and Quercusvelutina) coppice forests might be expected to have imbalanced absorptive and assimilative subsystems. Such rapid structural changes of individual shoots shown as changes of C-F ratio with the growth were observed in the analysis of Pasania edulis in the present study. The structures of clumps also change drastically in early stage of development (Ito et al., 1988b). It is, therefore, necessary to analyze the changes of clump structures in detail to discuss the productivity of sprouts.

\section{R elationship between reserved substances and vigor of sprouts}

It became clear that the vigor of sprouts mainly depends on the reserved substances because of the high correlations between net growth or number of sprouts and the original above ground biomass before cutting used as an index of reserved substances (Figs. 5, 6). Many researchers reported that some species reduce the vigor of sprouts if the age or the size of original stump exceeds a certain dagree (e. g., Mroz et al., 1984 ; Kamitnai, 1986). In Pasania edulis, it is emprically known that the vigor of sprouts begin to decline after attaining 30 years in their age and 10 or $15 \mathrm{~cm}$ in their dbh. Nevertheless, such a tendency was not observed in this study. The reason of this 
would be that the ages of original trees within the plot were almost same because of repetition of coppicing, and that they were cut at the age and the size around which they showed a peak of the vigor of sprouts.

Large fluctuations of $W s$ and $\mathrm{N}$ under the effect of $W a$ in Fig. 5 and Fig. 6 may result partly from that the original above ground biomass could not necessarily be a index of actual amount of reserved substances. Nevertheless, fluctuations in number of sprouts should be mainly influenced by the number of latent buds on which the number of sprouts may primarily depend. Gyokusen (1987a) found that, after the removal of sprouts, new sprouts with vascular traces connecting not to the pith directly but to the vascular traces of the former sprouts flushed though the positions of flushing did not increase, and he supposed them to originate from the buds which secondarily differentiated relatively later. Considering his observation, we can expect that many late-flushing sprouts which originate from the axillary buds of latent buds possibly appear after pre-existing sprouts fall down. The inference implies the large fluctuations in number of sprouts and their great influence on the total growth of sprouts per stump, because the total growth mainly depends of the number of sprouts established (Fig. 7).

Perennial grasses, which are the utilized for pasture, may reproduce the top after cutting in the same way as in the sprouts of woody plants. Studies on alfalfa suggest that total plant and total herbage yields of alfalfa during regrowth after cutting were directly related to the original plant size and carbohydrate root reserves, and were also dependent on the number and the size of buds on the stubble (Grandfield, 1943 ; Leach, 1968 ; Ueno and Smith, 1970). Further, Ueno and Smith (1970) found that numbers of shoots produced were proportional to the plant size. These results were supported in the case of sprouts of woody plants in this study.

In addition, Ueno and Smith (1970) found that proportion of the weight of total nonstructural carbohydrate (TNC) utilized until the minimum level of retained TNC were reached was the same for each plant size, and was only 27 to $33 \%$ of initial amounts. In the sprouts of Pasania edulis, even if the number of sprouts developed per unit reserved substances $(N / W a)$ decreases, i. e., the quota of reserved substances to each sprouts increase, the use efficiency of reserved substance $(W s / W a)$ decrease, because mean growth of individual sprouts $\left(W_{S} / N\right)$ shows only slight increase with increase of $\mathrm{Wa} / \mathrm{N}$ (Figs. 7-9). These results suggest the possibility that all of the reserved substances are not utilized for regrowth by sprouts of the woody plants same as in the tillering of perennial grasses, and that decreasing density of sprouts by detaching shoot will result in decline of productivity from the view point of the use efficiency of reserved substance.

As in above analysis, we adopted the original above ground biomass before cutting as the index of reserved substances, and assumed the biomass of sprouts at the end of the first growing season which include the growth depending on photosynthate after leaf expansion and ignore the dead shoots to be total regrowth. So $W s / W a$ does not indicate the use efficiency of reserved substance exactly. But, it may be worth considering in evaluation of productivity of sprouts. However, this efficiency were discussed on only the early growth stage, and it should be examined how this efficiency influences the growth in the later stage in considering forestry management, because only few stems would remain when they will be yielded. 


\section{CONCLUSION}

It became clear that the early growth of sprouts of Pasania edulis were far greater than those of seedlings developed in the same stand on both individual and unit area basis. The original tree size which might be related to the amount of the reserved substances, fairly influenced on the vigor of sprouts.

From the economical point of view of the dry matter production, seedling had more profitable dry matter allocation than those of sprouts at the earlier growth stage. This indicated that sprouts can make $\mathrm{C}-\mathrm{F}$ ratio disadvantageous so as to expand leaves at more advantageous position supported by the original root system.

Although these superiority of sprouts would result from great original root system as a source of substances required for regrowth and as an organ for absorbing water and minerals, large roots consume carbohydrates considerably through maintenance respiration. So, the dynamics of the original and newly formed roots are important factors to clarify the growth of sprouts. Nevertheless, it had not become clear and remains as one of the most important problems for further studies on the sprouts.

\section{REFERENCES}

Auclair, A. 1975 Sprouting response in Prunus serotina Erhr.: Multivariate analysis of site, forest structure and growth relationships. Am. Midl. Nat., $94:$ 72-87

Blake, T. J. 1980 Effect of coppicing on growth rate, stomatal characteristics and water relations in Eucalyptus camaldulensis Dehn. Aust. J. Plant Physiol., 7 : 81-87

Eliasson, L. 1961 The influence of growth substances on the formation of shoots from aspen roots. Physiol. Plant., 14: 150-156

Fujiwara, K. 1981 Phytosociological investigation of the evergreen broad-leaved forests of Japan -I-. Bull. Inst. Envir, Sci. Techn., Yokohama Natn. Univ., $7: 67-133$ (in Japanese with English summary)

Grandfield, C. 0. 1943 Food reserves and their translocation to the crown buds as related to cold and drought resistance in alfalfa. $J$. Agy. Res., 6'7 : 33-47

Grime, J. P. 1979 Plant strategies and vegetation processes. John Wiley and Suns, Chichester, pp. 153 $-154$

Gyokusen, K. 1977 (Influences of soil moisture environments on the distribution of plants (I) Water consumption and biomass production of several broad-leaved trees.) Bull. Kyushu Branch Jap. For.Soc., 30: 97-98 (in Japanese)*

Gyokusen, K. 1987a Studies on the sprout of Quercus acutissima Carr. (I) Morphological feature and situation of sprout development. Bull Kyushu Branch Jap. For. Soc., 40: $51-52$ (in Japanese)

Gyokusen, K. 1987b Studies on the sprout of Quercus acutissima Carr. (II) The feature of latent bud in mature tree. Trans. 98 th $\mathbf{M t g}$. Jap. For. Cos., 451-452 (in Japanese)

Gyokusen, K. 1988 Studies on the sprout of Quercus acutissimu Carr. (III) The effect of various cutting heights on the development and growth of sprout. Bull. Kyushu Branch Jap. For. Soc., 41 : 69-70 (in Japanese)

Hasegawa, S. 1984 Basic studies on the conservation of the natural coastal forests in Hokkaido. The structure and regeneration of Quercus dentata Thunb. forest in Ishikari. Bull. Hokkuido Univ. For., 41: 313-428 (in Japanese with English summary)

Hashizume, H. 1985 (Management of Shiitake (Lentinusedodes) bed logs forests (6) -Sprouting regeneration (1)-..) Kinjin, 31 (5) : 19-25 (in Japanese)*

Higo, M. 1987 Growth characteristics of Quercus mongolica var. gyosseseyyata, Tilia japonica and Acer mono seedlings. Bull. HokkaidoUniv, For. 44 : 139-152 (in Japanese with English summary)

Ito, S., T. Suzaki, T. Okano and H. Yahata 1988a Ecological studies on the coastal Pasania edulis 
forests in northern Kyushu. Sci. Bull. Fac. Agr. Kyushu Univ., 42: 163-186 (in Japanese with English summary)

Ito, S., T. Suzaki and H. Yahata 1988b Early growth of Pasania edulis coppice. Trans. 99 th M tg. Jap. For. Soc., 431-432 (in Japanese)

Ito, S. and T. Suzaki 1989 Comparisons of physiological and morphological characteristics between sprouts and seedlings of Pasania edulis established after clear-cutting. Bull. Kyushu Branch Jap. For. Soc., 42 (in printing) (in Japanese)

Iwaki, H. 1958 The influence of density on the dry matter production of Fagopyrumesculemtum. Jap. J. Bot., 16: 210-226

Johnson, P. S. 1979 Shoot elongation of black oak and white oak sprouts. Can. J.For. Res., 9 : 489 $-494$

Jones, R. H. and D. J. Raynal 1986 Spatial distribution and development of root sprouts in Fagus grandifolia (Fagaceae). Amer. J. Bot., 73 : 1723-1731

Jones, R. H. and D. J. Raynal 1987 Root sprouting in American beech (Fagus grandifolia): Production, survival and the effect of parent tree vigor. Can J. For. Res., 17 : 539-544

Jones, R. H. and D. J. Raynal 1988 Root sprouting in American beech (Fagus grandifolia) : Effect of root injury, root exposure and season. For. Ecol. Manage., 25 : 79-90

Kamitani, T. 1986 Studies on the process of formation of secondary beech forest in a heavy snowfall region (II) The relationship between stump age and the reproductive capacity for coppice sprouts of main woody species. J. Jap. For. Soc., 68 : 127-134 (in Japanese with English summary)

Karizumi, N. 1979 Illustrations of tree roots. Seibundo-shinkosha, Tokyo, pp. 353-356 (in Japanese)

Kormanik, P. P. and C. L. Brown 1967 Root bud and the development of root sucker in sweetgum. For. Sci., 4: 338-345

Kramer P. J. and T. T. Kozlowski 1960 Physiology of Trees. McGraw-Hill Book Company, Inc., New York, pp. 386-387

Kusumoto, T. 1957 Physiological and ecological studies on the plant production in plant communities. 4. Ecological studies on the apparent photosynthesis curve of evergreen broad-leaved trees. Bot.Mag. Tokyo., 70: 298-304

Merz, R. W. and S. G. Boyce 1956 Age of oak seedlings. J. For. 54 : 774-775

Miyawaki, A. 1981 Vegetation of Japan, vol. 2, Kyushu. Shibundo, Tokyo, pp. 77-172 (in Japanese)

Miyoshi, M. 1959 Studies on the management of Kashi (Cyclobalanopsis) and Shii (Shiia) evergreen broad-leaved forest in their native region. Bull. Miyazaki Univ. For., 3: 1-141 (in Japanese with English summary)

Mroz, G. D., D. J. Frederick and M. F. Jurgensen 1985 Site and fertilizer effects on northern hardwood stump sprouting. Can. J. For. Res., $15: 535-543$

Nakamura, S., H. Taoda, S. Kaminaka and K. Takeshita 1986 Natural regeneration of Castanopsis cuspidata forest (VI) Sprouting capacities of principal trees. Bull. Kyushu Branch Jap. For. Soc., 39 : 107-108 (in Japanese)

Ohkubo, T., M. Kaji and M. Hayama 1988 Structure of primary Japanese beech in the Chichibu Mountains, central Japan, with special reference to regeneration processes. Ecol. Res., 3: 101-116

Okano, T., T. Suzaki and S. Ito 1988 Evergreen broad-leaved forests in the upper warm-temperate zone (V) Emergence and mortality of seedlings of Cyclobalanopsis acuta. Trans. 99 th M tg. Jap. For. Soc., 423-424 (in Japanese)

Okitsu, S 1985 (Betula ermanii zone). In "Vegetation of Hokkaido", 4.2, ed. by K., Itoh, Hokkaido Univ. Press, Sapporo, pp. 168-199 (in Japanese)*

Powell, D. S. and E. H. Tryon 1979 Sprouting ability of advance growth in undisturbed hardwood stand. Can. J. For. Res., 9: 116-120

Shidei, T. and S. Saito 1979 (Illustrations of deciduous broad-leaved trees.) Kyoritsu Shuppan, Tokyo, pp. 6 (in Japanese)* 
Tohyama, M. 1965 Synecological studies on the Fagus japonica forest on Mt. Ohmuro, Yamanashi Pref.- The forest vegetation of Mt. Fuji —.Jpn.J. Ecol., 15 : 139-142 (in Japanese with English summary)

Tryon, E. H. and D. S. Powell 1984 Root ages of advance hardwood reproduction. For. Ecol. Manage., 8: 293-268

Tschaplinski, T. J. and T. J. Blake 1989 Photosynthetic reinvigoration of leaves following shoot decapitation and accelerated growth of coppice shoot. Physiol, Plant., 75 : 157-165

Ueno, M. and D. Smith 1970 Growth and carbohydrate changes in the root wood and bark of different sized alfalfa plants during regrowth after cutting. Crop Sci., $10: 396-399$

Ward, R. T. 1960 Some aspect of the regeneration habit of American beech. Ecology, 42 : 828-832

Yoda, K. 1971 (Forest ecology. In "Ecological Research Series" Vol. 4,) ed. by M. Numata, Tsukiji Shokan, Tokyo, pp. 27-28 (in Japanese)*

Zimmermann, M. H. and C. L. Brown (1971) Trees structure and function. Academic Press, Inc, New York, pp. 30-40

*The titles in parentheses are tentatively translated from the original Japanese titles by authors. 